\title{
A general method for identifying major hybrid male sterility genes in Drosophila
}

\author{
LING-WEN ZENG* \& RAMA S. SINGH† \\ Department of Ecology and Evolution, 1101 E. 57th Street, The University of Chicago, Chicago, IL 60637, U.S.A. and \\ $†$ †epartment of Biology, MCMaster University, 1280 Main Street West, Hamilton, Ontario, Canada L85 4K1
}

\begin{abstract}
The genes responsible for hybrid male sterility in species crosses are usually identified by introgressing chromosome segments, monitored by visible markers, between closely related species by continuous backcrosses. This commonly used method, however, suffers from two problems. First, it relies on the availability of markers to monitor the introgressed regions and so the portion of the genome examined is limited to the marked regions. Secondly, the introgressed regions are usually large and it is impossible to tell if the effects of the introgressed regions are the result of single (or few) major genes or many minor genes (polygenes). Here we introduce a simple and general method for identifying putative major hybrid male sterility genes which is free of these problems. In this method, the actual hybrid male sterility genes (rather than markers), or tightly linked gene complexes with large effects, are selectively introgressed from one species into the background of another species by repeated backcrosses. This is performed by selectively backcrossing heterozygous (for hybrid male sterility gene or genes) females producing fertile and sterile sons in roughly equal proportions to males of either parental species. As no marker gene is required for this procedure, this method can be used with any species pairs that produce unisexual sterility. With the application of this method, a small X chromosome region of Drosophila mauritiana which produces complete hybrid male sterility (aspermic testes) in the background of $D$. simulans was identified. Recombination analysis reveals that this region contains a second major hybrid male sterility gene linked to the forked locus located at either $62.7 \pm 0.66$ map units or at the centromere region of the $\mathrm{X}$ chromosome of $D$. mauritiana.
\end{abstract}

Keywords: hybrid sterility, reproductive isolation, speciation, spermatogenesis.

\section{Introduction}

Hybrid male sterility is the most common postzygotic reproductive isolating mechanism between closely related animal species and therefore has received special attention in the study of speciation. In animal species with heterogametic males (e.g. mammals and Drosophila), it is evident from large numbers of interspecific hybridizations (Wu \& Davis, 1993) that hybrid male sterility (with fertile hybrid females) is far more common than hybrid inviability. Genetic studies in Drosophila have accumulated evidence for major genes that control hybrid male sterility (Coyne \& Charlesworth, 1986; Pantazidis \& Zouros, 1988; Coyne \& Charlesworth, 1989; Orr, 1989a, 1992; Pantazidis et al., 1993; Perez et al., 1993). Although $\mathrm{Wu}$ and coworkers have

\footnotetext{
${ }^{*}$ Correspondence.
}

recently shown that epistatically interacting genes are very common in underlying hybrid male sterility (Cabot et al., 1994; Davis et al., 1994; Palopoli \& $\mathrm{Wu}, 1994)$, these studies do not exclude the involvement of major genes in hybrid male sterility.

In an attempt to detect genes responsible for hybrid male sterility, Dobzhansky (1936) used morphological markers to identify foreign chromosome segments linked to the markers in backcross progenies, and to examine the effects of the segments on male fertility. The outcome of his and subsequent studies on various groups of Drosophila species (Coyne, 1984; Coyne \& Kreitman, 1986; Orr, 1987, 1989b; Heikkinen \& Lumme, 1991; Khadem \& Krimbas, 1991) turned out to be virtually the same; every marker used is associated with hybrid male sterility and the largest effects are associated with Xchromosome markers. The strong association of hybrid sterility with the $\mathrm{X}$-chromosome markers has 
led to the postulation that the $\mathrm{X}$ chromosome has evolved more rapidly, between different species, than autosomes (Charlesworth et al., 1987; Coyne \& Orr, 1989). Our recent study in Drosophila simulans and $D$. sechellia using two-dimensional electrophoresis (2DE) has shown that the large effect of the $\mathrm{X}$ chromosome is not caused by generally higher divergence of the $X$ chromosome than the autosomes (Zeng \& Singh, 1993b). This implies that a few major genes may be responsible for the large effect of the $\mathrm{X}$ chromosome. If there exist major genes with large effects, we should be able to identify and map them individually. Researchers attempting to identify and map major genes linked to X-chromosome markers have used an extension of Dobzhansky's backcross analysis approach (Dobzhansky, 1936). In this method, the marked chromosome segments of one species are introgressed into the background of another species by continuous backcrosses (Wu \& Beckenbach, 1983; Coyne \& Charlesworth, 1986; Naveira \& Fontdevila, 1986; Pantazidis \& Zouros, 1988; Coyne \& Charlesworth, 1989; Naveira \& Fontdevila, 1991a,b; Pantazidis et al., 1993; Perez et al., 1993; Cabot et al., 1994; Palopoli \& Wu, 1994). The putative hybrid male sterility genes are then mapped by recombination analysis (Coyne \& Charlesworth, 1986; Pantazidis \& Zouros, 1988; Coyne \& Charlesworth, 1989; Orr, 1989a) or by other genetic and molecular means (Pantazidis et al., 1993; Perez et al., 1993; Cabot et al., 1994; Palopoli \& Wu, 1994).

A general problem of this marker-assisted backcross method is that the introgressed segments are usually very large and it is not known if the segments carry major genes or many polygenes (Naveira, 1992). Using introgression of regions marked by three X-chromosome markers in Drosophila simulans and D. mauritiana, Coyne \& Charlesworth (1989) showed three major hybrid male sterility genes linked to the three markers, whereas Naveira (1992) showed (using some of the same markers) that the introgressed regions carried polygenes with an additive threshold effect on male fertility.

This method is also limited by the availability of markers. It can detect only genes closely linked to the markers used; genes which are not closely linked to any marker can not be detected. Not only are identification and mapping difficult in species groups without abundant morphological and molecular markers (deletion, inversion, asynapsis and DNA markers), but also the detection of sterility genes is biased towards the marked segments of the chromosomes.
Here, we introduce a simple method which is free of these problems. In this method, individual major hybrid male sterility genes, or tightly linked gene complexes, are introgressed from one species into the background of another species by continuous backcrosses. This is performed by selecting females, each generation, that are heterozygous for the sterility gene (and which therefore produce both fertile and sterile sons in equal proportions) and backcrossing them to males of one of the parental species. No marker is required for this introgression, which makes the method one of general use. Once a major gene(s) has been detected it can be mapped and characterized by using conventional genetic and/ or molecular techniques.

By applying this method to two closely related species, Drosophila simulans and D. mauritiana, a major factor or closely linked factors has been identified and mapped to the $D$. mauritiana $X$ chromosome. This factor(s), which functions normally in $D$. mauritiana, causes complete male sterility when placed in the background of $D$. simulans.

\section{Materials and methods}

\section{Species stocks, markers and fly culture}

Drosophila simulans and $D$. mauritiana stocks were obtained from Dr Jean David. A D. simulans strain homozygous for a recessive mutant marker on each of its five major chromosome arms was obtained from Dr Jerry Coyne. For the purpose of this study, only three markers were actually used. The three mutant markers used are forked (bristle) on the $\mathrm{X}$ chromosome ( $f, \mathrm{I}-56.7)$, net (wing veins) on the second chromosome ( $n t$, II-0), and ebony (body colour) on the third chromosome (e, III-71). All the stocks and crosses were reared in 8-dram vials on banana medium at $24-25^{\circ} \mathrm{C}$ and a $12 \mathrm{~h}$ light/dark regime.

\section{Classification of hybrid males and fertility measurement}

The method for classifying hybrid males and measuring male fertility is the same as described in Zeng \& Singh (1993a). In $F_{1}$ and backcross generations of $D$. simulans and $D$. mauritiana, we found two types of sterile males: males with atrophied testes (type 1 males) and males with normal shaped testes but with no mature sperm in their seminal vesicles (type 2 males). The two types of sterile males appeared in comparable frequencies in the 
first backcross generation (Table 1). Although both type 1 and type 2 males are sterile, the sterility genes involved are different (L.-W. Zeng \& R. S. Singh, unpublished results) and in the present paper a gene or genes responsible for type 2 male sterility is reported. There were also two types of fertile males both of which had normal testes and large quantities of mature sperm in their seminal vesicles. The difference between these two types of males is that the amount of sperm produced by one type (type 3 ) is about half of the 'normal' amount (type 4). For simplification, in the present study the two types of fertile males are sometimes combined and referred to as type $3 / 4$. Male fertility was measured by the combined proportion of type 3 and type 4 males (or type 3/4). This method has been shown to be very reliable (Zeng \& Singh, 1993a). All males were aged for 5 to 6 days before being dissected for fertility scoring.

\section{Introgression of hybrid male sterility genes}

$F_{1}$ hybrid females from crossing $D$. simulans females to $D$. mauritiana males were backcrossed to $D$. simulans males. The progeny produced by the first backcross generation was denoted as $\mathrm{BC}_{1} \cdot \mathrm{BC}_{1}$ females were individually backcrossed to $D$. simulans males again (one female with one to three males) and thus a number of matriarchal families $\left(\mathrm{BC}_{1}\right.$ families) were established. The sons from each family were dissected and their fertility was scored. This measure of fertility of the sons from each family was used as an indication of whether or not the mother of the family carried any major hybrid male sterility gene (from $D$. mauritiana). If the mother carried a major male sterility gene, half of her sons would receive the gene and be sterile. Similarly, the male sterility gene would be passed to half of her daughters.

The daughters of one of the sterility-gene-carrying mothers (which produced about 50 per cent sterile males) were individually backcrossed to $D$. simulans males again and a number of second generation backcross $\left(\mathrm{BC}_{2}\right)$ families were formed. The sons from each of the $\mathrm{BC}_{2}$ families were examined for fertility and the daughters of one of the sterilitygene-carrying mothers were used to perform the next generation backcross. This backcrossing scheme was continued for 45 generations.

By continuously backcrossing a female carrying a male sterility gene to $D$. simulans, the genetic composition of the resulting backcross offspring was gradually substituted by that of $D$. simulans. The gene or genes from $D$. mauritiana responsible for hybrid male sterility were selectively introgressed into the background of $D$. simulans. In the present backcross method, a given introgression line would carry only one sterility gene (or a tightly linked gene block). All other $D$. mauritiana genes were eliminated by the recombination and segregation processes. As only one female was chosen in each backcross generation to make the consecutive backcrosses, the progressive reduction of the introgressed region by recombination was very efficient. Independent introgression lines may carry different genes if more than one major gene is involved in sterility.

\section{Results}

\section{Male fertility of parental species, $F_{1}$ hybrids and first generation backcross progeny}

Table 1 shows the proportions of the four types of males in $D$. simulans, $D$. mauritiana, $\mathrm{F}_{1}$ hybrids and progeny of the first backcross generation. Most of the males in the two parental species were type 4 males and the fertility was very high ( $>95$ per cent). $F_{1}$ hybrid males from crossing $D$. simulans females to $D$. mauritiana males were completely sterile consisting of all type 2 males. When the hybrid females were backcrossed to $D$. simulans males, the male offspring produced were mostly of type 1 and type 2 with a small proportion of type 3 and type 4 (or type 3/4) males (6.0 per cent).

Table 1 Male fertility of Drosophila simulans, D. mauritiana, the $\mathrm{F}_{1}$ hybrids and the first generation backcross $\left(\mathrm{BC}_{1}\right)$ progeny

\begin{tabular}{lrrrrrr}
\hline & \multicolumn{3}{c}{ Male type } & & \\
\cline { 2 - 4 } & 1 & 2 & 3 & 4 & Total & $\begin{array}{c}\text { Fertility (\%) } \\
\text { (Type 3/4) }\end{array}$ \\
\hline D. simulans & 0 & 7 & 0 & 152 & 159 & 95.6 \\
D. mauritiana & 1 & 4 & 0 & 184 & 189 & 97.4 \\
$\mathrm{~F}_{1}$ & 0 & 72 & 0 & 0 & 72 & 0.0 \\
$\mathrm{BC}_{1}$ & 113 & 152 & 14 & 3 & 282 & 6.0 \\
\hline
\end{tabular}

The $\mathrm{F}_{1}$ hybrid males were obtained from crossing $D$. simulans females to $D$. mauritiana males. $\mathrm{BC}_{1}$ males were obtained by crossing the $\mathrm{F}_{1}$ hybrid females to $D$. simulans males. Males were classified into four types (type 1 to 4 ) based on the shape and size of their testes and the amount of sperm produced. Type 1 males had atrophied testes with no or few sperm. Type 2 males had normal shaped testes but with no or few sperm. Both type 3 and type 4 males had normal shaped testes and large quantity of sperm, the difference was that type 4 males had normal amounts of sperm and type 3 males had about half as much. The fertility was measured by the combined proportion of type 3 and type 4 males (or type 3/4). 
Table 2 Male types and numbers produced in the first ten and the last seven of the 45 generations of backcrosses (BC)

\begin{tabular}{|c|c|c|c|c|c|c|c|c|c|c|c|c|c|c|c|}
\hline \multirow{2}{*}{$\begin{array}{l}\text { Male } \\
\text { type }\end{array}$} & \multicolumn{15}{|c|}{ Family } \\
\hline & 1 & 2 & 3 & 4 & 5 & 6 & 7 & 8 & 1 & 2 & 3 & 4 & 5 & 6 & 7 \\
\hline & $\mathrm{BC}_{1}$ & & & & & & & & $\mathrm{BC}_{2}$ & & & & & & \\
\hline 1 & 3 & 1 & 2 & 1 & 11 & 1 & 6 & 6 & 0 & 0 & 0 & 2 & 0 & 19 & 0 \\
\hline 2 & 1 & 7 & 7 & 2 & 6 & 6 & 2 & 9 & 1 & 14 & 9 & 11 & 8 & 3 & 12 \\
\hline $3 / 4$ & 2 & 4 & 5 & 3 & 3 & 8 & 6 & 2 & 18 & 20 & 7 & 8 & 6 & 6 & 15 \\
\hline Total & $\begin{array}{c}6 \\
\mathrm{BC}_{3} *\end{array}$ & 12 & 14 & 6 & 20 & 15 & 14 & 17 & $\begin{array}{l}19 \\
\mathrm{BC}_{4}\end{array}$ & 34 & 16 & 21 & 14 & 28 & 27 \\
\hline 1 & 0 & 0 & 9 & 1 & 0 & 0 & 0 & & 0 & 0 & & & & & \\
\hline 2 & 9 & 7 & 11 & 10 & 11 & 13 & 0 & & 0 & 11 & & & & & \\
\hline $3 / 4$ & 12 & 4 & 4 & 5 & 12 & 9 & 9 & & 23 & 19 & & & & & \\
\hline Total & $\begin{array}{l}21 \\
\mathrm{BC}_{5}\end{array}$ & 11 & 24 & 16 & 23 & 22 & 9 & & $\begin{array}{l}23 \\
\mathrm{BC}_{6}\end{array}$ & 30 & & & & & \\
\hline 1 & 0 & 2 & 0 & 0 & 0 & 0 & 0 & 0 & 0 & 0 & 0 & & & & \\
\hline 2 & 5 & 3 & 7 & 1 & 8 & 2 & 7 & 3 & 0 & 6 & 2 & & & & \\
\hline 4 & 4 & 10 & 4 & 14 & 8 & 8 & 4 & 5 & 11 & 7 & 8 & & & & \\
\hline Total & $\begin{array}{c}9 \\
\mathrm{BC}_{7}\end{array}$ & 15 & 11 & 15 & 16 & 10 & 11 & 8 & $\begin{array}{l}11 \\
\mathrm{BC}_{8}\end{array}$ & 13 & 10 & & & & \\
\hline 2 & 0 & 1 & 3 & 1 & 10 & 0 & 6 & 6 & 2 & 1 & 7 & 1 & 0 & 7 & 4 \\
\hline 4 & 16 & 6 & 3 & 7 & 5 & 12 & 7 & 5 & 11 & 10 & 9 & 16 & 13 & 9 & 9 \\
\hline Total & $\begin{array}{l}16 \\
\mathrm{BC}_{9}\end{array}$ & 7 & 6 & 8 & 15 & 12 & 13 & 11 & $\begin{array}{l}13 \\
\mathrm{BC}_{10}\end{array}$ & 11 & 16 & 17 & 13 & 16 & 13 \\
\hline 2 & 0 & 10 & 1 & 6 & 0 & 0 & 0 & 0 & 0 & 4 & & & & & \\
\hline 4 & 5 & 8 & 9 & 6 & 14 & 11 & 6 & 4 & 4 & 5 & & & & & \\
\hline Total & $\begin{array}{c}5 \\
\mathrm{BC}_{39}\end{array}$ & 18 & 10 & 12 & 14 & 11 & 6 & 4 & $\begin{array}{c}4 \\
\mathrm{BC}_{40}\end{array}$ & 9 & & & & & \\
\hline 2 & 0 & 5 & 0 & 8 & 0 & 0 & 7 & 0 & 6 & 7 & 4 & 0 & 8 & & \\
\hline 4 & 13 & 5 & 8 & 5 & 15 & 11 & 5 & 10 & 5 & 6 & 4 & 12 & 5 & & \\
\hline Total & $\begin{array}{l}13 \\
\mathrm{BC}_{41}\end{array}$ & 10 & 8 & 13 & 15 & 11 & 12 & 10 & $\begin{array}{l}11 \\
\mathrm{BC}_{42}\end{array}$ & 13 & 8 & 12 & 13 & & \\
\hline 2 & 5 & 5 & 0 & 3 & 5 & 4 & 5 & 6 & 5 & 0 & 3 & & & & \\
\hline 4 & 7 & 4 & 12 & 6 & 7 & 8 & 12 & 8 & 4 & 9 & 4 & & & & \\
\hline Total & $\begin{array}{l}12 \\
\mathrm{BC}_{43}\end{array}$ & 9 & 12 & 9 & 12 & 12 & 17 & 14 & $\begin{array}{c}9 \\
\mathrm{BC}_{44}\end{array}$ & 9 & 7 & & & & \\
\hline 2 & 0 & 7 & 4 & 6 & 0 & 0 & 9 & 0 & 6 & 5 & & & & & \\
\hline 4 & 8 & 9 & 5 & 5 & 8 & 9 & 4 & 15 & 13 & 13 & & & & & \\
\hline Total & 8 & 16 & 9 & 11 & 8 & 9 & 13 & 15 & 19 & 18 & & & & & \\
\hline 2 & $\mathrm{BC}_{45}$ & & & & & & & & $\mathrm{BC}_{45}$ & ntins & & & & & \\
\hline 4 & $\begin{array}{l}9 \\
8\end{array}$ & $\begin{array}{r}0 \\
20\end{array}$ & $\begin{array}{l}11 \\
15\end{array}$ & $\begin{array}{r}0 \\
18\end{array}$ & $\begin{array}{r}7 \\
13\end{array}$ & $\begin{array}{r}13 \\
6\end{array}$ & $\begin{array}{l}19 \\
15\end{array}$ & $\begin{array}{r}0 \\
26\end{array}$ & 16 & 20 & 0 & 15 & 0 & & \\
\hline Total & 17 & 20 & 26 & 18 & 20 & 19 & 34 & $\begin{array}{l}26 \\
26\end{array}$ & $\begin{array}{l}14 \\
30\end{array}$ & $\begin{array}{l}12 \\
32\end{array}$ & $\begin{array}{l}20 \\
20\end{array}$ & $\begin{array}{l}16 \\
31\end{array}$ & $\begin{array}{l}27 \\
27\end{array}$ & & \\
\hline
\end{tabular}

The recurrent parent of the backcrosses was Drosophila simultans. The families of $\mathrm{BC}_{n}$ generation were formed by individually backcrossing female offspring of the $n$th generation backcross to $D$. simultans males. A sample of sons of each family was dissected for fertility checking (male type scoring). The daughters from one of the families which produced about or higher than 50 per cent sterile males were selected for the next generation backcross. The numbers of the four types of males in each family at each generation are given in the table. In the first 10 generations, the families selected to propagate the next generations are indicated in bold face. Type 3/4 are mostly type 4 males with very few type 3 males.

From the sixth backcross generation on, virtually no type 1 or type 3 males were observed and the columns for male type 1 and 3 are left out.

*In $\mathrm{BC}_{3}$, families 1-2, 3-4, 5-7 were derived from families 2, 6 and 7 in $\mathrm{BC}_{2}$, respectively. In all other backcross generations all families were derived from a single family from the previous generation. 
Introgression of a gene or gene block responsible for complete hybrid male sterility from $D$. mauritiana into the background of $D$. simulans

By using the introgression scheme described in the Materials and methods, a hybrid male sterility gene or gene block with large effect was introgressed from $D$. mauritiana into the background of $D$. simulans by 45 generations of backcrosses. Table 2 shows the family segregation data for the first 10 and the last seven backcross generations.

Eight $\mathrm{BC}_{1}$ (the first backcross generation) females were individually backcrossed to $D$. simulans males and eight families ( $\mathrm{BC}_{1}$ families) were established. The numbers of the four types of males in each of the eight families are given in Table 2. In most of the $\mathrm{BC}_{1}$ families, type 1 and type 2 males were still produced, which means that the mothers carried genes responsible for both type 1 and type 2 male sterility. Seven virgin females were collected from one of the eight families $\left(\mathrm{BC}_{1}\right.$ - family 6 , Table 2$)$ to carry out the second generation backcross, and seven $\mathrm{BC}_{2}$ families were generated. Of the seven $\mathrm{BC}_{2}$ families, some were segregating type 2 and type $3 / 4$ males, some were still segregating type 1 , type 2 and type $3 / 4$ males. The mothers of the families which segregate type 2 and type $3 / 4$ males may carry a gene or genes (in heterozygous state) responsible for type 2 male sterility. The mothers of the families which segregate for type 1 , type 2 and type $3 / 4$ males may carry genes responsible for both type 1 and type 2 male sterility.

Three $\mathrm{BC}_{2}$ families were selected to carry out the third generation of backcrossing, two (families 2 and 7) of which had a segregation of type 2 and type $3 / 4$ males, and one (family 6 ) had a segregation of type 1 , type 2 and type $3 / 4$ males (Table 2 ). The data in Table 2 show that the $\mathrm{BC}_{3}$ families $(1,2,5,6$, and 7$)$ derived from families 2 and 7 in the previous generation were still segregating for type 2 and type $3 / 4$ males and the families ( 3 and 4 ) derived from family 6 in previous generation were still segregating for all four types of males. As family 3 produced both types of sterile males, the mother may carry genes responsible for the sterility of both type 1 and type 2 males. So this family was selected to make the fourth generation backcross. However, only type 2 sterile males were produced in the $\mathrm{BC}_{4}$ generation and, for the rest of the 45 generations, the backcrossing was continued by using families producing type 2 sterile sons (Table 2).

The segregation pattern in the subsequent backcross generations (Table 2) is the same: some families produced no sterile males and some produced about half type 2 (sterile) and half type 4 (fertile) males. This indicates that the mothers of the former families carried no sterility gene and the mothers of the latter families carried a gene (or gene complex) for aspermic testes (type 2 males). Assuming one hybrid male sterility (hms) gene was introgressed we can denote the $D$. mauritiana allele as $h m s^{m a}$, the homologous $D$. simulans allele as $h m s^{s i}$, the females carrying the sterility gene as $h \mathrm{~ms}^{\mathrm{si}} / \mathrm{hms}^{\mathrm{ma}}$ (heterozygous) and the females not carrying the sterility gene as $h m s^{s i} / h m s^{s i}$ (homozygous, the same as pure D. simulans).

\section{The introgressed hms gene behaves as a single Mendelian factor with complete penetrance}

From the fourth backcross generation onward, the introgressed hms gene (one gene is assumed) responsible for aspermic testes (type 2 males) segregated in a manner of a single major Mendelian factor. The type 2 and type 4 males produced by every heterozygous female in $\mathrm{BC}_{4}$ or later generation families are roughly in equal proportions (Table 2). A chi-square test of the combined data of males produced by heterozygous females (from $\mathrm{BC}_{4}$ on) in Table 3 shows that the segregation ratio of type 2 $\left(h m s^{m a} / Y, 348\right)$ and type $4\left(h m s^{s i} / Y, 370\right)$ males is not significantly different from the $1: 1$ ratio $\left(\chi_{1}^{2}=0.674, P>0.2\right.$, Table 3$)$. The numbers of homozygous (nonsterility gene carriers, $h m s^{s i} / h m s^{s i}$ ) and heterozygous (sterility gene carriers, $h m s^{s i} / h m s^{m a}$ ) females also showed a 1:1 ratio (Table 3 ). From the $\mathrm{BC}_{4}$ generation on (data in Table 2), there were 48 females (or families) which produced type 2 and type 4 males (i.e. heterozygous females) and 37 females (or families) which produced all type 4 males (i.e. homozygous females). The ratio of

Table 3 Segregation ratio (1:1) of the hybrid male sterility gene $(\mathrm{hms})$ in the backcross generations

\begin{tabular}{lcc}
\hline Genotype & No. of males & No. of females \\
\hline$h m s^{s i} / h m s^{s i}\left(\right.$ or $\left.h m s^{s i} / Y\right)$ & 370 & 37 \\
$h m s^{s i} / h m s^{m a}\left(\right.$ or $\left.h m s^{m a} / Y\right)$ & 348 & 48 \\
$\chi^{2}$ & 0.674 & 1.424 \\
Probability & $>0.2$ & $>0.2$ \\
\hline
\end{tabular}

The numbers of males and females are pooled data from $\mathrm{BC}_{4}$ onward in Table 2. Females which produced none, one or two sterile males were considered as homozygous $\left(h m s^{s i} / h m s^{s i}, N=37\right)$, and the rest were considered as heterozygous $\left(\mathrm{hms}^{\mathrm{si}} / \mathrm{hms}^{\mathrm{ma}}, N=48\right)$. The numbers of fertile and sterile males are the sum of the sterile and fertile males produced by all the 48 heterozygous females. 
heterozygous females to homozygous females is not significantly different from the expected ratio of $1: 1$ $\left(\chi_{1}^{2}=1.424, P>0.2\right.$; Table 3$)$.

A segregation ratio of $1: 1$ for type 2 (sterile) and type 4 (fertile) males produced by heterozygous females indicates that the expression of the introgressed hms gene has a complete penetrance. The probability that a son receives the introgressed gene from his heterozygous mother is 50 per cent, and the proportion of sterile sons (or type 2 males) is also 50 per cent. The 1:1 ratio of sterile to fertile males produced by heterozygous females indicates that the introgressed gene by itself can cause complete male sterility.

\section{Mapping of the hms gene}

As the introgressed $h m s$ gene behaves as a single Mendelian factor with complete penetrance in expression, we can use conventional recombination analysis to map this factor. A $D$. simulans strain with three morphological markers on each of the three major chromosomes $(f ; e$; $n t)$ was used to map the gene. Virgin females produced by a heterozygous mother $\left(h m s^{s i} / h m s^{m a}\right)$ from the 45th backcross generation were individually crossed to males of the marker strain. The genotypes $\left(f^{+} / f ; e^{+} / e ; n t^{+} / n t\right.$; $h m s^{s i} / h m s^{m a}$ or $f^{+} / f ; e^{+} / e ; n t^{+} / n t ; h m s^{s i} / h m s^{s i}$ ) of these females were identified by the fertility scores of their sons. The female progenies produced by two of the females with the genotype $f^{+} / f ; e^{+} / e ; n t^{+} / n t$; $h m s^{s i} / h^{m} s^{m a}$ were again individually backcrossed to $f ; e ; n t ; h m s^{s i}$ males (the marker strain), and a number of families were formed. The segregation pattern in these families remained the same: some families produced all fertile males and some produced about half fertile and half sterile males. The males produced by the former families were dis-

Table 4 Numbers of males with different genotypes produced in the mapping cross

\begin{tabular}{|c|c|c|c|c|c|c|c|c|c|c|c|c|c|c|}
\hline \multirow{2}{*}{$\begin{array}{l}\text { Backcross male } \\
\text { genotype }\end{array}$} & \multicolumn{14}{|c|}{ Family } \\
\hline & 1 & 2 & 3 & 4 & 5 & 6 & 7 & 8 & 9 & 10 & 11 & 12 & 13 & Total \\
\hline 1. $f^{+} ; e^{+} ; n t^{+} ; h m s^{m a}$ & 21 & 11 & 8 & 11 & 9 & 10 & 14 & 16 & 15 & 9 & 14 & 15 & 17 & 17 \\
\hline 2. $f^{+} ; e^{+} ; n t^{+} ; h m s^{s}$ & 1 & 0 & 0 & 0 & 0 & 0 & 0 & 0 & 0 & 0 & 0 & 0 & 1 & \\
\hline 3. $f^{+} ; e^{+} ; n t ; \mathrm{hms}^{m a}$ & 14 & 10 & 8 & 6 & 5 & 19 & 12 & 12 & 29 & 8 & 10 & 16 & 12 & 161 \\
\hline 4. $f^{+} ; e^{+} ; n t ; h m s^{s i}$ & 0 & 0 & 0 & 0 & 0 & 0 & 0 & 1 & 0 & 0 & 0 & 0 & 0 & 1 \\
\hline 5. $f^{+} ; e ; n t^{+} ; h m s^{m a}$ & 16 & 14 & 15 & 15 & 9 & 17 & 12 & 14 & 23 & 13 & 11 & 12 & 23 & 194 \\
\hline 6. $f^{+} ; e ; n t^{+} ; h m s^{s i}$ & 0 & 0 & 0 & 0 & 0 & 0 & 0 & 0 & 1 & 0 & 0 & 0 & 0 & 1 \\
\hline 7. $f^{+} ; e ; n t ; h m s^{m a}$ & 15 & 18 & 11 & 10 & 10 & 10 & 7 & 9 & 27 & 7 & 8 & 7 & 14 & 153 \\
\hline 8. $f^{+} ; e ; n t ; h m s^{s i}$ & 1 & 0 & 0 & 0 & 0 & 0 & 0 & 0 & 0 & 0 & 0 & 0 & 0 & 1 \\
\hline 9. $f ; e^{+} ; n t^{+} ; h m s^{m a}$ & 2 & 0 & 2 & 0 & 1 & 2 & 2 & 1 & 1 & 0 & 1 & 1 & 0 & 13 \\
\hline 10. $f ; e^{+} ; n t^{+} ; h m s^{s i}$ & 10 & 7 & 7 & 7 & 4 & 12 & 11 & 11 & 22 & 4 & 9 & 8 & 9 & 121 \\
\hline 11. $f ; e^{+} ; n t ; h m s^{m a}$ & 3 & 1 & 0 & 1 & 0 & 3 & 1 & 0 & 4 & 1 & 1 & 0 & 3 & \\
\hline 12. $f ; e^{+} ; n t ; h m s^{s i}$ & 11 & 3 & 2 & 1 & 5 & 8 & 6 & 10 & 17 & 3 & 6 & 6 & 10 & \\
\hline 13. $f ; e ; n t^{+} ; h m s^{m a}$ & 2 & 0 & 0 & 0 & 1 & 3 & 3 & 2 & 2 & 0 & 2 & 2 & 1 & 8 \\
\hline 14. $f ; e ; n t^{+} ; h m s^{s i}$ & 9 & 8 & 4 & 6 & 7 & 8 & 9 & 4 & 12 & 3 & 11 & 8 & 6 & 95 \\
\hline 15. $f ; e ; n t ; h m s^{m a}$ & 1 & 1 & 2 & 1 & 1 & 0 & 3 & 0 & 2 & 0 & 2 & 0 & 1 & 14 \\
\hline 16. $f ; e ; n t ; h m s^{s i}$ & 6 & 6 & 9 & 3 & 7 & 6 & 12 & 5 & 12 & 3 & 3 & 7 & 7 & 86 \\
\hline
\end{tabular}

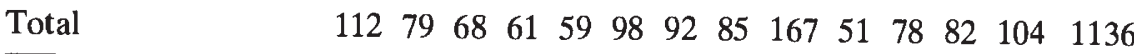

Males from a Drosophila simulans marker strain with the $D$. simulans allele of the $h m s$ gene $\left(f / Y ; e / e ; n t / n t ; h m s^{s i}\right)$ were crossed to females heterozygous for the $h m s$ gene $\left(f^{+} / f^{+} ; e^{+} / e^{+} ; n t^{+} / n t^{+} ; h m s^{s i} / h m s^{m a}\right)$. Female offspring produced by the above cross $\left(f^{+} / f ; e^{+} / e ; n t^{+} / n t ; h m s^{s i} / h m s^{m a}\right.$ and $f^{+} / f ; e^{+} / e ; n t^{+} / n t ; h m s^{s i}$ $h m s^{s i}$ ) were individually backcrossed to the males of the marker strain. Only the males produced by the $f^{+} / f ; e^{+} / e ; n t^{+} / n t ; h m s^{s i} / h m s^{m a}$ females were scored for marker phenotypes and fertility. The males produced by females with the genotype $f^{+} / f ; e^{+} / e ; n t^{+} / n t ; h m s^{s i} / h m s^{s i}$ were discarded. The numbers of males of each genotype produced by each female (or family) are shown in the table, which are used to calculate the recombination frequencies between the hms gene and each of the three marker genes (see Table 5). 
Table 5 Recombination frequencies $(r)$ between the hybrid male sterility gene $(\mathrm{hms})$ and the markers

\begin{tabular}{lccc}
\hline Gene pair & No. of recombinants & Total & $r \pm$ SE (\%) \\
\hline$h m s-f$ & 68 & 1136 & $6.0 \pm 0.66$ \\
$h m s-e$ & 591 & 1136 & $52.0 \pm 1.18$ \\
$h m s-n t$ & 565 & 1136 & $49.7 \pm 1.35$ \\
$f-e$ & 589 & 1136 & $51.8 \pm 1.44$ \\
$f-n t$ & 563 & 1136 & $49.6 \pm 1.28$ \\
$e-n t$ & 576 & 1136 & $50.7 \pm 1.27$ \\
\hline
\end{tabular}

The $r$ values are weighted means calculated from the data on 13 families presented in Table 4.

Table 6 Linkage of the hybrid male sterility with the forked locus $(f)$ (summarized from Table 4)

\begin{tabular}{lllr}
\hline Genotype & Sterile & Fertile & Total \\
\hline+ & 678 (parental) & 5 (recombinants) & 683 \\
$f$ & 63 (recombinants) & 390 (parental) & 453 \\
Total & 741 & 395 & 1136 \\
\hline
\end{tabular}

carded and the males produced by the latter families (13 families, Table 4), which resemble progeny of a test-cross, were scored for the marker phenotype and fertility. The data shown in Table 4 were used to calculate recombination frequencies between the putative $\mathrm{hms}$ gene and each of the three mutant marker genes (Table 5). The recombination frequencies between the hms gene and two autosomal mutant markers (net, nt: II-0; ebony, e: III-71) are close to 50 per cent (Table 5). This means that the introgressed $\mathrm{hms}$ gene is unlinked to these markers. On the other hand, the recombination frequency between the hms gene and the X-chromosome mutant marker forked ( $f: \mathrm{I}-56.7)$ is 6.0 per cent. This suggests that the introgressed gene is on the $X$ chromosome located about $6 \mathrm{cM}$ (centimorgans) away from the forked locus. Pooling data from 13 families gave a standard error of 0.66 per cent for the distance between forked and the introgressed gene (Table 5). The same recombination frequency ( 6 per cent) is obtained by using a maximum likelihood method with the data in Table 4 summarized in Table 6, which also gives a standard deviation of 0.7 per cent (calculations not shown). The recombination frequencies of the three pairwise mutant markers are close to 50 per cent as expected, because they are on three separate chromosomes (Table 5).

(C) The Genetical Society of Great Britain, Heredity, 75, 331-341.

\section{Discussion}

\section{A method for detecting major hybrid male sterility genes}

The backcross method used in this study along with the selection of females which produce fertile and sterile sons in approximately equal proportions ensures that the selected females carry a gene or genes (from the donor species) which can cause complete male sterility. If a major gene is carried by the female, half of her daughters would inherit the gene and thus the introgression can proceed further. On the other hand, if many unlinked genes each with a minor effect are the only basis of the male sterility, these genes would be separated by the processes of recombination and segregation and would then be randomly passed on to different daughters, none or few of which would inherit a full set of polygenes required to produce complete sterility. Because we selected carrier females which produce fertile and sterile sons in approximately equal proportions, the present scheme guarantees detection of any major genes that affect hybrid male fertility. Obviously, in the case where several independent major genes are involved, they will be separated by recombination and segregation and only one of them would be kept in a given introgression line by the continuous backcrosses. However, if a tightly linked gene complex is involved which behaves as a single major gene, the present backcrossing scheme would not be able to disrupt the linkage. When more than one gene is required to render complete hybrid male sterility and these genes are closely linked (Cabot et al., 1994; Palopoli \& Wu, 1994), these genes would be identified as a major gene when the linkage is tight. When these genes showing epistasis are loosely linked or unlinked, they would not be identified by using this method. Once a gene or genes is identified by using this method, a finer mapping or other molecular study is required to pinpoint the exact location and to tell if only one major gene, or more closely linked genes, are involved in producing the complete sterility.

The number of backcrosses required to screen for major genes in a given species pair does not have to be large. Once a female which gives about 50 per cent sterile sons is chosen in the first backcross generation, a second backcross would tell if she carries any major gene. If she carries one or more major genes, about half or more of her daughters would carry the gene(s) and therefore produce 50 per cent or more sterile sons. If none of her daughters produces about or higher than 50 per cent sterile males, she does not carry any major sterility gene. 
In the species pair $D$. simulans and $D$. mauritiana, an obvious 1:1 segregation ratio among males and females can be seen in the first two and three generations. To demonstrate the persistence of the 1:1 segregation ratio and to reduce the introgressed region linked to the $h m s$ gene, we did 45 generations of backcrosses.

It should be pointed out that, like all other previously used methods, this method preferentially detects X-linked sterility genes, and only dominant autosomal sterility genes can be detected. This bias in methodology has led to the identification of more hybrid sterility factors on the $\mathrm{X}$ chromosome than on the autosomes, and consequently the postulation that the $\mathrm{X}$ chromosome has the largest effects in postzygotic reproductive isolation.

\section{Hybrid male sterility associated with the forked locus}

A tight linkage between hybrid male sterility and the marker forked was first revealed by Coyne (1984) using Dobzhansky's backcross analysis (Dobzhansky, 1936). Assuming that the sterility resulted from a single major gene, Coyne \& Charlesworth (1986, 1989 ) introgressed the forked region from $D$. mauritiana into $D$. simulans by repeated backcrosses and mapped this gene at 1.1 map units from the forked locus using a maximum likelihood method. In an attempt to map this gene at a finer scale, Perez et al. (1993) introgressed segments of various sizes around the forked region from $D$. mauritiana into the background of $D$. simulans, and mapped a major gene (named Ods) within polytene chromosome bands $16 \mathrm{D}$ and $16 \mathrm{E}$, or about 1.1 map units proximal to the forked locus (calculated from the data in Table 1 in Perez et al., 1993), which is the exact position defined by Coyne \& Charlesworth (1986). However, when a small region covering polytene chromosome bands $16 \mathrm{D}$ and $16 \mathrm{E}$ was introgressed, no sterility was observed (C.-I Wu, personal communication; Wu \& Palopoli, 1994). Therefore, they infer that the presence of another gene distal or proximal to the Ods is required to render male sterility.

The identified $h m s$ does not seem to be the same as the previously identified gene (Ods). The recombination frequency between the hms and the forked locus ( 6 per cent) is much larger than 1.1 per cent. Therefore there must be another gene or genes in this region which cause complete hybrid male sterility independently or with $O d s$ together. If one major gene is responsible for our sterility introgression, this gene is $6.0 \pm 0.66$ map units away from the forked locus. The distal location of the mapping
$(50.7 \pm 0.66)$ corresponds roughly to the cytological location ranging from band $13 \mathrm{~F}$ to $14 \mathrm{~A}$ of the polytene chromosome. The region distal to the forked locus covering and exceeding band $13 \mathrm{~F}$ of the polytene chromosome of $D$. mauritiana, when introgressed into the background of $D$. simulans, does not cause male sterility (Perez et al., 1993). The identified $\mathrm{hms}$ gene must be proximal to the forked locus and located at position $62.7 \pm 0.66$ on the $\mathrm{X}$ chromosome.

Around the position 62.7 on the $\mathrm{X}$ chromosome, many loci have been reported to affect male fertility in D. melanogaster. At least five different male sterility mutations have been isolated and mapped to the cytological bands from $18 \mathrm{~F}$ to $20 \mathrm{BC}$ (Geer et al., 1979; Dybas et al., 1981). It would be interesting to know if hybrid male sterility results from regulatory miscues of conserved structural genes.

There are a number of other possibilities regarding the number and nature of the sterility gene or genes within the sterility introgression. There can be more than one closely linked gene responsible for the complete sterility introgression, and the genes may cause complete sterility independently or they may need to be together to cause sterility as shown by Palopoli \& Wu (1994). These possibilities are examined by using the maximum likelihood method. Standard maximum likelihood equations were developed based on different models in which the number and nature of the sterility gene or genes vary. The results show that the only model which gives positive estimates of recombination frequencies is the one with two major genes (each of them produce complete sterility) on one side of the forked locus. The estimated recombination frequencies between the forked locus and the two genes are $0.73 \pm 0.33$ per cent (one standard deviation) and $13.8 \pm 1.6$ per cent, respectively. The models with more than one gene together causing sterility (each individual sterility gene by itself has no effect) are incompatible with the mapping data (Table 6). This can also be seen directly from the mapping data in Table 6, in which there are more $f$ sterile (63) than $f^{+}$fertile (5) males. Models with two major genes with one on each side of the forked locus, and models with more than two major genes do not give meaningful estimates of the recombination frequencies (calculations not shown).

In the two major genes model, as both of the genes are on one side of the forked locus and regions distal to the forked locus have no sterility effect (Perez et al., 1993), they must be proximal to forked. The recombination frequency $0.73 \pm 0.33$ per cent is comparable with the previously identified 
major sterility factor $(O d s)$, and it is possible that the same gene has been picked up in the present study. The putative location of the other gene is then around the centromere. This raises the possibility that both the Ods gene and the heterochromatic centromere of the $D$. mauritiana $\mathrm{X}$ chromosome have been introgressed. It is known in $D$. melanogaster that deficiency of the $\mathrm{X}$ heterochromatin causes male sterility. The sperm of these deficient males fail to become individualized and are degraded (Peacock et al., 1975; McKee \& Lindsley, 1978; Merrill et al., 1992). The phenotype is very similar to the Type 2 sterile males produced from the introgression. The testes are normal with immature spermatids but the seminal vesicles which store mature (individualized) sperm are empty.

\section{The role of major and minor genes in hybrid male sterility}

A central question concerning the nature of genes involved in reproductive isolation remains unanswered: i.e. is hybrid sterility or inviability caused by the cumulative effect of many minor genes, or by the action of a few major genes, each with a discrete effect (Perez et al., 1993)? The involvement of major genes in hybrid inviability is suggested by the isolation of mutations that rescue inviable hybrids (Watanabe, 1979; Hutter \& Ashburner, 1987; Hutter et al., 1990; Sawamura et al., 1993a,b). However, for hybrid sterility, the issue remains controversial. Although by using marker-assisted introgression of chromosome segments a number of major gene candidates have been identified and mapped (Coyne \& Charlesworth, 1986, 1989; Pantazidis \& Zouros, 1988; Orr, 1989a; Pantazidis et al., 1993; Perez et al., 1993), the introgressed segments are usually very large and it is difficult to determine if the effects of the introgressed segment result from mainly major genes or only from a large number of minor genes. It is this problem that has recently led to a renewed controversy on the role of major/minor genes.

The introgression studies with the Drosophila buzzatii species group (Naveira \& Fontdevila, 1986, 1991a,b) show that the effects of most introgressed segments are caused by a large number of genes each with small effect (polygenes). On the other hand, in the species pairs $D$. simulans/D. mauritiana and $D$. simulans $/ D$. sechellia, Coyne \& Charlesworth (1989) introgressed three marked regions of $D$. mauritiana (or $D$. sechellia) into $D$. simulans and mapped three major genes on the $\mathrm{X}$ chromosome. However, contradictory results have been obtained in the same pair of species for the same introgressed regions. Naveira (1992) introgressed two of the three regions studied by Coyne \& Charlesworth (1989) and has shown that the sterility effects associated with these regions are polygenic, and, therefore raised the possibility that most of the previously identified 'major genes' (Coyne \& Charlesworth, 1986, 1989; Pantazidis \& Zouros, 1988; Orr, 1989a) may be polygenes. While there are no data verifying other identified 'major genes', the two major genes identified and mapped in the forked region support Coyne \& Charlesworth's (1986, 1989) conclusion. Their results in the species pair $D$. simulans and $D$. sechellia are also verified by a parallel study in our laboratory (L.-W. Zeng \& R. S. Singh, unpublished results). By using the new method in the species pair $D$. simulans $/ D$. sechellia, we have identified two major genes in the forked and yellow-white regions. The map positions of the two major genes are comparable to those obtained by Coyne \& Charlesworth (1989).

The data from the present study suggest that both major and minor genes are involved in hybrid male sterility. This is shown by the fact that hybrid male sterility can arise from multiple developmental defects producing atrophied testes (type 1 males) or from failure in mature sperm production (type 2 males). The disappearance of type 1 males (atrophied testes) in the first few generations of the backcross experiment (Table 2) indicates that this type of sterility may involve polygenes or multiple epistatically interacting genes (Cabot et al., 1994; Davis et al., 1994). On the other hand, the sterility of type 2 males (aspermic testes) may involve both major and minor genes. The method described here is meant to detect only major genes. By using this method with other species pairs, we can examine the existence of any major gene.

\section{Acknowledgments}

We would like to thank Drs Jerry Coyne and Jean David for providing fly stocks and Drs Hiroshi Akashi, Jerry Coyne, Douglas Davidson, Martin Kreitman, Tony Long, Richard Morton, Michael Wade and Chung-I Wu for discussions and comments on this manuscript. This work was supported by a research grant from the Natural Sciences and Engineering Research Council of Canada to R.S.S.

\section{References}

CABOT, E. L., DAVIS, A. W., JOHNSON, N. A. AND WU, C.-I. 1994. Genetics of reproductive isolation in the Droso- 
phila simulans clade: complex epistasis underlying hybrid male sterility. Genetics, 137, 175-189.

CHARLESWORTH, B., COYNE, J. A. AND BARTON, N. H. 1987. Relative rates of evolution of sex chromosomes and autosomes. Am. Nat., 130, 113-146.

COYNE, J. A. 1984. Genetic basis of male sterility in hybrids between two closely related species of Drosophila. Proc. Natl. Acad. Sci. U.S.A., 81, 4444-4447.

COYNE, J. A. AND CHARLESWORTH, B. 1986. Localization of an X-linked factor causing sterility in male hybrids between two closely related species of Drosophila. Heredity, 57, 243-246.

COYNE, J. A. AND CHARLESWORTH, в. 1989. Genetic analysis of X-linked sterility in hybrids between three sibling species of Drosophila. Heredity, 62, 97-106.

COYNE, J. A. AND KREITMAN, M. 1986. Evolutionary genetics of two sibling species, Drosophila simulans and $D$. sechellia. Evolution, 40, 673-691.

COYNE, J. A. AND ORR, H. A. 1989. Two rules of speciation. In: Otte, D. and Endler, J. (eds) Speciation and its Consequences, pp. 189-211. Sinauer Press, Sunderland, MA.

DAVIS, A. W., NOONBURG, E. G. AND WU, C.-I. 1994. Evidence for complex genic interactions between conspecific chromosomes underlying hybrid female sterility in the Drosophila simulans clade. Genetics, 137, 191-199.

DOBZHANSKY, Th. 1936. Studies on hybrid sterility. II. Localization of sterility factors in Drosophila pseudoobscura hybrids. Genetics, 21, 113-135.

DYBAS, L. K., TYL, B. T. AND GEER, B. W. 1981. Aberrant spermiogenesis in X-linked male-sterile mutants of Drosophila melanogaster. J. Exp. Zool., 216, 299-310.

GEER, B. W., BOWMAN, J. T. AND TYL, B. 1979. A gene necessary for late sperm function in Drosophila melanogaster. J. Exp. Zool., 209, 387-394.

HEIKKINEN, E. AND LUMME, J. 1991. Sterility of male and female hybrids of Drosophila virilis and Drosophila lummei. Heredity, 67, 1-11.

HUTTER, P. AND ASHBURNER, M. 1987. Genetic rescue of inviable hybrids between Drosophila melanogaster and its sibling species. Nature, 327, 331-333.

HUTTER, P., ROOTE, J. AND ASHBURNER, M. 1990. A genetic basis for the inviability of hybrids between sibling species of Drosophila. Genetics, 124, 909-920.

KHADEM, M. AND KRIMBAS, с. в. 1991. Studies of the species barrier between Drosophila subobscura and $D$. madeireusis. I. The genetics of male hybrid sterility. Heredity, 67, 157-165.

McKEE, B. AND LINDSLEY, D. L. 1978. Inseparability of Xheterochromatic functions responsible for $\mathrm{X}: \mathrm{Y}$ pairing, meiotic drive and male fertility in Drosophila melanogaster. Genetics, 116, 399-407.

MERRILL, C. J., CHAKRAVARTI, D., HABERA, L., DAS, S., EISENHOUR, L. AND McKEE, B. 1992. Promoter-containing ribosomal DNA fragments function as $\mathrm{X}-\mathrm{Y}$ meiotic pairing sites in D. melanogaster males. Devl. Genet., 13, 468-484.

NAVEIRA, H. 1992. Location of X-linked polygenic effects causing sterility in male hybrids of Drosophila simulans and $D$. mauritiana. Heredity, 68, 211-217.

NAVEIRA, H. AND FONTDEVILA, A. 1986. The evolutionary history of Drosophila buzzatii. XII. The genetic basis of sterility in hybrids between $D$. buzzatii and its sibling $D$. serido from Argentina. Genetics, 114, 841-857.

NAVEIRA, H. AND FONTDEVILA, A. 1991a. The evolutionary history of Drosophila buzzatii. XXI. Cumulative action of multiple sterility factors on spermatogenesis in hybrids of $D$. buzzatii and D. koepferae. Heredity, 67, $57-72$.

NAVEIRA, H. AND FONTDEVILA, A. 1991b. The evolutionary history of Drosophila buzzatii. XXII. Chromosomal and genic sterility in male hybrids of $D$. buzzatii and $D$. koepferae. Heredity, 66, 233-240.

ORR, H. A. 1987. Genetics of male and female sterility in hybrids of Drosophila pseudoobscura and D. persimilis. Genetics, 116, 555-563.

ORR, H. A. 1989a. Localization of genes causing postzygotic isolation in two hybridizations involving Drosophila pseudoobscura. Heredity, 63, 231-237.

ORR, H. A. 1989b. Genetics of sterility in hybrids between two subspecies of Drosophila. Evolution, 43, 180-189.

ORR, H. A. 1992. Mapping and characterization of a 'speciation' gene in Drosophila. Genet. Res., 59, 73-80.

PALOPOLI, M. F. AND WU, C.-I. 1994. Genetics of hybrid male sterility between Drosophila sibling species: a complex web of epistasis is revealed in interspecific studies. Genetics, 138, 1-13.

PANTAZIDIS, A. C., GALANOPOULOS, V. K. AND ZOUROS, E. 1993. An autosomal factor from Drosophila arizonae restores normal spermatogenesis in Drosophila mojavensis males carrying the $D$. arizonae $\mathrm{Y}$ chromosome. Genetics, 134, 309-318.

PANTAZIDIS, A. C. AND ZOUROs, E. 1988. Location of an autosomal factor causing sterility in Drosophila mojavensis males carrying the Drosophila arizonensis $\mathrm{Y}$ chromosome. Heredity, 60, 299-304.

PEACOCK, W. J., MIKLOS, G. L. G. AND GOODCHILD, D. J. 1975. Sex chromosome meiotic drive systems in Drosophila melanogaster. I. Abnormal spermatid development in males with a heterochromatin-deficient $\mathrm{X}$ chromosome $\left(s c^{4} s c^{8}\right)$. Genetics, 79, 613-634.

PEREZ, D. E., WU, C.-I., JOHNSON, N. A. AND WU, M.-L. 1993. Genetics of reproductive isolation in the Drosophila simulans clade: DNA marker-assisted mapping and characterization of a hybrid-male sterility gene, Odysseus (Ods). Genetics, 134, 261-275.

SAWAMURA, K., TAIRA, T. AND WATANABE, T. 1993a. Hybrid lethal systems in the Drosophila melanogaster species complex. I. The maternal hybrid rescue $(\mathrm{mhr})$ gene of Drosophila simulans. Genetics, 133, 299-305.

SAWAMURA, K., YAMAMOTO, M.-T. AND WATANABE, T. K. 1993b. Hybrid lethal systems in the Drosophila melanogaster species complex. II. The Zygotic hybrid rescue (Zhr) gene of D. melanogaster. Genetics, 133, 307-313.

WATANABE, T. 1979. A gene that rescues the lethal hybrids between Drosophila melanogaster and D. simulans. Jap. J. Genet., 54, 325-331.

(c) The Genetical Society of Great Britain, Heredity, 75, 331-341. 
WU, C.-I. AND BECKENBACH, A. 1983. Evidence for extensive genetic differentiation between the sex ratio and the standard arrangement of Drosophila pseudoobscura and $D$. persimilis and identification of hybrid sterility factors. Genetics, 105, 71-86.

WU, C.-I. AND DAVIS, A. W. 1993. Evolution of postmating reproductive isolation: the composite nature of $\mathrm{Hal}-$ dane's rule and its genetic bases. Am. Nat., 142, $187-212$.

WU, C.-I. AND PALOPOLI, M. 1994. Genetics of postmating reproductive isolation in animals. Ann. Rev. Genet., 27,
283-308.

ZENG, L.-W. AND SINGH, R. S. 1993a. The genetic basis of Haldane's rule and the nature of asymmetric hybrid male sterility between Drosophila simulans, D. mauritiana and D. sechellia. Genetics, 134, 251-260.

ZENG, L.-W. AND SINGH, R. S. 1993b. A combined classical genetic and high resolution two-dimensional electrophoretic approach to the assessment of the number of genes affecting hybrid male sterility in Drosophila simulans and Drosophila sechellia. Genetics, 135, 135-147. 